УДК 373.3.091

DOI:

Людмила Силюга, кандидат фізико-математичних наук, доиент кафедри математики, інформатики та методики їх викладання у початковій школі Дрогобииького державного педагогічного університету імені Івана Франка

Тарас Вепрів, магістр факультету початкової та мистецької освіти Дрогобицького державного педагогічного університету імені Івана Франка

\title{
ДИДАКТИЧНІ ПРИНЦИПИ ВИХОВАННЯ ІНФОРМАЦІЙНОЇ КУЛЬТУРИ УЧНІВ ПОЧАТКОВӦ̈ ШКОЛИ
}

У статті досліджується проблема формування інформаційної культури учнів початкових класів. Висвітлено теоретико-методичні основи формування інформаційної культури молодших школярів при вивченні навчальних дисциплін. Сформульовані основні принциии побудови дидактичної системи інформаційної підготовки молодших школярів. Охарактеризовані компоненти комп 'ютерної грамотності учнів початкової школи. Визначені організаційні форми, методи і засоби навчання учнів молодщого шкільного віку в системі формування інформаційної культури в умовах інформаційного інтернет-середовища.

Ключові слова: інформаційна культура; початкова школа; молодші школярі; інформаційнокомунікаційні технологї; дидактичні принцчини.

תim. 8.

Lyudmyla Sylyuha, Ph.D.(Physical and Mathematical Sciences), Associate Professor of the Mathematics, Informatics and Methods of Teaching them at Primary School Department Drohobych Ivan Franko State Pedagogical University

Taras Vepriv, Master of the Faculty of Primary and Artistic Education Drohobych Ivan Franko State Pedagogical University

\section{DIDACTIC PRINCIPLES OF UPBRINGING OF INFORMATION CULTURE OF PRIMARY SCHOOL PUPILS}

The article deals with the problem of formation of the informational culture of primary school pupils. The theoretical and methodological foundations of formation of the informational culture of pupils at studying of educational disciplines are described. The main, most important principles of constructing the didactic system of informational preparation of junior schoolchildren are formulated. The important components of computer literacy of primary school pupils are characterized. The complex of rules for the teacher's leadership formation of informational behavior of pupils are developed. Defined organizational forms, methods and means of teaching pupils of primary school in the system of formation of the information culture in the conditions of information Internet environment.

It is important for the teacher to be able to use intelligent information technologies (databases, knowledge bases, systems of artificial intelligence, in particular expert systems, video-text systems, telematics, information and other means of storage, processing, transmission and presentation of information). At the same time, it is essential to have the ability to organize, systematize, structure data and knowledge, understanding the essence of information modeling, the ways of presenting data and knowledge.

In the educational process for the development in the pupils of primary school of information competence, it is important to consider such didactic principles as the principle of availability, the principle of continuity and systemicity, the principle of reliance on the positive, the principle of humanization, the principle of integration of disciplines of the natural and humanitarian cycles.

Propedeutics of information culture is oriented on the development of cognitive activity of pupils and their creative potential, aimed at forming the flexibility and criticality of thinking, promoting the ability to think in categories, separating the main thing from minor, analyzing the situation and drawing conclusions, developing their objective and abstract components.

Keywords: an informational culture; a primary school; pupils of primary school; information-communicational technologies; didactic principles.

П остановка проблеми. Сучасне інформаційне суспільство формує нову систему цінностей, у якій володіння знаннями, уміннями й навичками $є$ необхідним, але недостатнім результатом освіти. Людина повинна орієнтуватися в інформаційних потоках, освоювати нові технології, шукати і використовувати нові знання. У зв'язку з такою 
постановкою питання актуальність проблеми виховання інформаційної культури учнів молодшого шкільного віку є надзвичайно важливою на сьогодні, адже вміння самостійно мислити, спираючись на знання й досвід, цінується вище, ніж просто ерудиція, володіння знаннями без уміння застосовувати їх для вирішення конкретних проблем.

Зважаючи на необхідність формування інформаційної культури молодших школярів, актуальним завданням стає розгляд дидактичних принципів цього процесу.

Аналіз останніх джерел і публікацій. На основі теоретичного аналізу наукової літератури нами встановлено, що поняття “інформаційна культура" багатозначне і характеризується складністю та багатовимірністю. Невизначеність поняття "інформаційна культура" посилюється наявністю багатьох близьких, але не тотожних йому за змістом понять: “культура читання”, “інформаційна грамотність”, “комп’ютерна грамотність”. Значущими в контексті розгляду питання формування інформаційної культури особистості є наукові дослідження Л.С. Винарик, А.М. Коломійця [2], О.В. Матвієнко [4], О.В. Пруднікової [6] та інших. Як вважає О.В. Малишевський, інформаційна культура $\epsilon$ одним із найголовніших факторів формування гармонійно розвиненої особистості. Високий рівень інформаційної культури учнів $\epsilon$ передумовою двох найголовніших вмінь - вміння адекватно формалізувати знання, які вони мають, і вміння адекватно їх інтерпретувати [3].

У працях багатьох учених та учителів (В. Шолохович, С. Антонова, М. Левшин, С. Оленєв, Є. Семенюк, Н. Зінов'єва, М. Назаренко, Р. Гуревич, Н. Баловсяк, О. Немиров, В. Кравець, В. Кухаренко, Н. Новожилова та ін.) досліджуються методики формування інформаційної культури молодого покоління, аналізуються форми навчальної роботи, доцільність використання засобів і прийомів для розвитку інформаційної культури на ефективність навчального процесу. Проблема комп'ютеризації освіти, розробка програмного забезпечення та методики використання інформаційних технологій унавчанні достатньо розкриті в роботах О.М. Бахтина, А.Ю.Барановського, Б.С.Гершунського, М.С.Голованя, M.I. Жалдака, I.I. Мархела, С.I. Машбиця, Н.В. Морзе та ін.

Мета статті. Визначення дидактичних принципів становлення і розвитку інформаційної культури учнів початкової школи.

Виклад основного матеріалу. Становлення сучасної системи освіти насамперед оріснтовано на входження у світовий освітній простір. Виникає потреба у різнобічному підході до вивчення знань в цілому, а встановлення зв'язків між окремими галузями знань стає вкрай необхідним. Враховуючи інтенсивність інформатизації всіх сфер життя та діяльності суспільства, особливого значення набувають питання інформатизації освіти: розробляються різноманітні варіанти іiі змісту, використовуються величезні можливості сучасної дидактики для підвищення ефективності освітніх структур; науково розробляються i практично обгрунтовуються нові ідеї та технології; посилюється роль розвиваючої функції навчання.

Враховуючи вимоги сучасної освіти, учителю необхідно володіти високим ступенем інформаційної культури та вільно орієнтуватися в широкому спектрі сучасних інноваційних технологій, ідей, шкіл, напрямів, а також ставити перед собою завдання прищепити інформаційну культуру учням, починаючи вже $з$ молодших класів, навіть 3 першого ж уроку [2]. Важливо підкреслити, що молодші школярі вже на початкових етапах навчання у школі повинні засвоювати основи інформаційної культури для досягнення певних позитивних результатів.

“Загальні положення формування основ інформаційної культури молодших школярів спрямовані на розв'язання питань управління 3 виростанням ергастичного навчання та за допомогою ПК; розвитку діалогу з комп'ютером, комунікативних властивостей учнів, які формуються при роботі із комп'ютером (розуміння учнем команд ПК, знання їх, уміння чітко їх формулювати, писемна мова, вміння чітко формулювати запитання, готовність до “спілкування” 3 комп'ютером); організації навчального процесу у школі з використанням комп'ютера; становленні операційноалгоритмічного та функціонального стилів мислення, особистісних якостей школярів; формуванні системності знань та інформаційної картини світу, інформаційної інтуїції” $[7,105]$.

Коли мова йде про формуванням інформаційної культури учнів початкових класів, необхідно будувати процес навчання і виховання, спираючись на наступні принципи: принцип наступності i системності, принцип доступності, принцип опори на позитивне, принцип гуманізації, принцип інтеграції дисциплін. Принцип наступності - це поступове, від класу до класу, ускладнення матеріалу із збереженням цілісності предмету, покликаного не тільки озброїти учнів сукупністю знань та умінь щодо роботи з інформацією, а й сформувати системне уявлення про інформаційну картину світу, інформаційний світогляд. Згідно 3 принципом доступності навчання будується 3 
урахуванням рівня підготовки учнів, їхніх вікових та індивідуальних особливостей. Принцип опори на позитивне передбачає співробітництво, терпіння і зацікавлену участь вчителя у навчанні і вихованні учнів. Принцип гуманізації-це гуманне відношення до особистості учня, повага його прав і свобод, повага до позиції учня навіть тоді, коли він відмовляється виконувати пред'явлені вимоги, ненасильницьке формування якостей, що від нього вимагаються. Принцип інтеграції дисциплін природничого і гуманітарного циклів припускає включення у процес викладання природничих дисциплін елементів гуманітарних знань. На наш погляд, вчитель, починаючи розділ, нову тему, знайомлячи учнів із новими сучасними інформаційними технологіями, повинен приділити увагу історії відкриттів явищ або процесів, що лежать в основі технології, що вивчається, розповісти учням про те, як вони вплинули на долю людей, згадати про винахідників, про те, як це відкриття вплинуло на їх особисту долю [8].

“Тому виховання інформаційної культури в учнів початкової школи необхідно розпочинати 3 формування наступних умінь:

- виділяти, осмислювати, формулювати інформаційний запит;

- вірно вибирати джерело інформації відповідно до отриманого завдання;

- оцінювати адекватність джерела інформації отриманому завданню;

- раціонально вести пошук і ефективно працювати з будь-якими доступними джерелами інформаціі;

- виділяти головне та відсікати другорядне при обробці інформації;

- структурувати і змінювати об'єм інформації відповідно до учбового завдання" [5, 9].

Необхідно ретельно продумати поєднання слова вчителя з засобами ІКТ, можливості використання різних методичних прийомів: пояснення, установка на сприймання перед демонструванням окремих елементів комплексу чи комплексу загалом, бесіда за їх змістом; пояснення (бесіда) за змістом аудіовізуальних засобів; демонстрація окремих частин, фрагментів або кадрів, що чергується 3 розповіддю (поясненням); демонстрація, що супроводжується поясненням (синхронним коментуванням) [1].

"У формуванні основ інформаційної культури молодших школярів окрім оволодіння основами алгоритмічного мислення суттєвими $є$ такі методи інформатики як формалізація (подання інформації у знаково-символічній формі; виокремлення у ній суттєвих характеристик та основних ознак; поділ на взаємопов'язані частини, які несуть навчальнопізнавальне навантаження), моделювання (складання моделей математичних задач, природних явищ) та проектування способів розв'язування завдань 3 практичним змістом за допомогою ПК” [7, 107].

Педагог, який вводить своїх учнів в інформаційний віртуальний світ, повинен володіти наступними основними навичками, що висувають до учасників освітньо-інформаційного Інтернетсередовища: міцне, усвідомлене володіння основами знань про процеси перетворення, передачі та використання інформації, розкриття значення інформаційних процесів у формуванні сучасної наукової картини світу, ролі сучасних інформаційних технологій у розвитку суспільства [2]. Реалізація подібних вимог дозволяє закласти фундамент, на основі якого можна формувати інформаційну культуру школяра.

“Комп'ютерна грамотність - це знання, уміння, навички в галузі інформатики, потрібні кожному для ефективного використання у своїй діяльності комп'ютерних технологій. Важливими компонентами комп'ютерної грамотності $€$ знання про використання комп'ютера у різних сферах виробництва, культури, освіти, а також про зміни в діяльності людини, котрі пов'язані з його використанням; знання будови і функціональних можливостей комп'ютерної техніки; володіння сучасними програмними засобами. У процесі опанування комп'ютерної грамотності формуються вміння використовувати комп’ютер під час написання та редагування тексту, пошуку інформації, малювання тощо, складати прості програми, алгоритми розв'язування задач" $[8,20]$. На базі комп'ютерної грамотності формується інформаційна культура учнів.

Діяльнісний вимір предметної ІКТ компетентності пов'язаний з такими вміннями дітей молодшого шкільного віку:

\section{технологічними:}

- сприймати інформацію від учителя 3 підручників та електронних джерел;

- обмінюватися інформацією в спілкуванні між собою;

- отримати початкові навички використання різноманітних засобів інформаційних технологій для вирішення навчальних завдань;

- читати та змінювати тексти, визначати ключові слова в тексті, створювати та опрацьовувати текст;

- сприймати різноманіття графічних даних: зображення, фото, карти, схеми, діаграми;

- створювати власні зображення у вигляді малюнків та творчо опрацьовувати готові зображення; 
- презентувати інформацію у вигляді слайдів;

- описувати об'єкти реальної дійсності різними способами - у вигляді чисел, тексту, зображень, схем, таблиць, презентацій;

\section{телекомунікаційними:}

- усвідомлювати свої інформаційні потреби та прагнути до їх задоволення через пошук;

- безпечно спілкуватись з використанням IКТ, а також співпрацювати, допомагати одноліткам, навчатись разом з іншими;

- сприймати різні точки зору, брати участь у дискусії, розуміти чужу точку зору, прислухатись до неї;

\section{алгоритмічними та логічними:}

- формулювати команди для виконавця, складати алгоритми за зразком, шукати помилки в послідовності команд, аналізувати зміст завдань на складання алгоритму для виконавців;

- шукати різні варіанти виконання завдань, обирати та обгрунтовувати найефективніший варіант виконання;

- розрізняти істинні та хибні висловлювання, формулювати висловлювання 3 логічним слідуванням.

Збільшення питомої ваги інформаційних повідомлень 3 різних джерел вимагає від учня володіння на достатньому рівні умінням критично ставитися до інформаційних даних, точно відображати сутність повідомлень, переробляти, зберігати та відтворювати інформацію. Інформаційне середовище молодших школярів пропорційно (прямо чи обернено) впливає на формування особистісного освітнього ядра, оскільки міра повноти, достовірності, новизни та цінності інформації розвиває пізнавальні процеси, активізує світоглядну позицію, збагачує навчально-пізнавальний досвід учня.

“Послідовний і грамотно продуманий розвиток інформаційної культури школярів зрештою, призведе до розвитку в учнів особистісної потреби у процесі засвоєння основ інформаційної культури, умінь самостійно здійснювати пошук інформації, усувати інформаційний дефіцит, сприятиме розвитку вмінь щодо взаємодії з інформаційним середовищем, умінь моделювати власну інформаційну поведінку, а також розвине здатність до грамотного сприйняття й оцінці інформації' $[5,12]$.

Висновки і пропозиції. Проблема формування у школярів інформаційної культури має не тільки свою історію розвитку, а й характеризується багатьма підходами до іï теоретичного осмислення та практичного розв'язання. Формування інформаційної культури учнів початкової школи забезпечує розвиток компетентності особистості в цілому та підготовку до успішного життя в сучасному суспільстві. Інформаційну культуру у молодшому шкільному віці не слід зводити тільки до комп'ютерної грамотності. Підхід до іiі формування не може бути прийнятним тільки через вивчення інформатики, тому що він веде до звуження поняття “інформаційна культура”. Формуючи інформаційну культуру, потрібно враховувати анатомо-фізіологічні, психологічні особливості молодшого шкільного віку. Воно можливе лише за чіткої взаємодії освітнього Інтернетсередовища, учителя, учня і батьків. Навчальновиховне середовище школи, де вчителі та учні $є$ учасниками інформаційного Інтернетсередовища, що вільно володіють новими інноваційними моделями комунікаційних технологій, значно сприяють формуванню власної інформаційної культури школярів.

\section{ЛІТЕРАТУРА}

1. Гончарова О.М. Організаційні форми, методи і засоби навчання в системі формування інформаційної культури учнів. Комп'ютерно орієнтовані системи навчання. Київ: вид-во НПУ ім. М.П. Драгоманова, 2000. №2. C. 282-285.

2. Коломієць А.М. Інформаційна культура вчителя початкових класів. Вінниця, 2007.379 с.

3. Малишевський О. В. Пропедевтика інформаційної культури учнів основної школи. Умань, 2009. 236 с.

4. Матвієнко О.В. Інформаційна культура особистості: освітньо-виховний контекст: навч. метод.посіб. Київ, 2006. 115 с.

5. Онопченко О. Формування інформаційної культури учнів початкової школи в умовах інформаційного інтернет-середовища. Навчання i виховання обдарованої дитини: теорія та практика: Збірник наукових праць. Випуск 12. Київ, 2014. С. 6-13.

6. Пруднікова О.В. Інформаційна культура: концептуальні засади та світоглядний сенс. Харків, 2015.351 с.

7. Фадєєва Т.О. Інформатична компетентність вчителя початкових класів. Наукові записки. Випуск: 68. Серія: Математичні науки. Кіровоград, 2009. С.102-108.

8. Формування інформаційної культури учнів загальноосвітніх навчальних закладів: Наук.-метод. рек. / АПН України. ДНПБ України ім. В.О. Сухомлинського. Упоряд. А.І. Рубан; Наук. консультант Я.О. Чепуренко; Наук. ред.: П.І. Рогова, В.І. Лутовинова; Рецензент С.А. Медведєва; Літ. ред. Л.І. Стельмах; Відп. за вип. I.I. Хемчян. Київ, 2005. 117 с.

\section{REFERENCES}

1. Honcharova, O.M. (2000). Orhanizatsiini formy, metody $i$ zasoby navchannia $v$ systemi formuvannia informatsiinoi kultury uchniv. Kompiuterno oriientovani systemy navchannia [Organizational forms, methods and means of teaching in the system of formation of information culture of students. Computer-based learning systems]. Kyiv: National Pedagogical Dragomanov University Publ., No.2. pp. 282-285. [in Ukrainian]. 


\section{СТРУКТУРА ТА ПЕДАГОГІЧНІ УМОВИ ФОРМУВАННЯ САМООСВІТНЬОЇ КОМПЕТЕНТНОСТІ МАЙБУТНІХ ФАХІВЦІВ}

2. Kolomiiets, A.M. (2007). Informatsiina kultura vchytelia pochatkovykh klasiv [Informational culture of the primaty school teacher]. Vinnytsia, 379 p. [in Ukrainian].

3. Malyshevskyi, O.V. (2009). Propedevtyka informatsiinoi kultury uchniv osnovnoi shkoly [The propedevtika information culture of secondary school pupils]. Uman, 236 p. [in Ukrainian].

4. Matviienko, O.V. (2006). Informatsiina kultura osobystosti: osvitno-vykhovnyi kontekst [Information culture of the individual: educational context]. Educational textbook. Kyiv, 115 p. [in Ukrainian].

5. Onopchenko, O. (2014). Formuvannia informatsiinoi kultury uchniv pochatkovoi shkoly $\mathrm{v}$ umovakh informatsiinoho internet-seredovyshcha [Formation of informational culture of elementary school pupils in the conditions of information internet-environment]. Training and education of a gifted child: theory and practice:
Collection of scientific articles. Vol. 12. Kyiv, pp. 6-13. [in Ukrainian].

6. Prudnikova, O.V. (2015). Informatsiina kultura: kontseptualni zasady ta svitohliadnyi sens [Information culture: conceptual foundations and ideological meaning]. Kharkiv, 351 p. [in Ukrainian].

8. Fadieieva, T.O. (2009). Informatychna kompetentnist vchytelia pochatkovykh klasiv [Informational competence of elementary school teacher]. Scientific notes. Vol. 68 Series: Mathematical Sciences. Kirovohrad, pp.102-108. [in Ukrainian].

9. Formuvannia informatsiinoi kultury uchniv zahalnoosvitnikh navchalnykh zakladiv [Formation of informational culture of pupils of general educational institutions]. Scientific and methodical recommendations. National Academy of Pedagogical Sciences of Ukraine. V.O. Sukhomlynskyi State Scientific and Pedagogical library of Ukraine. Kyiv, 2005. 117 p. [in Ukrainian].

Стаття надійшла до редакції 04.07.2019

УДК 377.3.046 (043.5)

DOI:

Наталія Самарук, кандидат педагогічних наук, доиент кафедри вищої математики та комп'ютерних застосувань Хмельницького національного університету

\section{СТРУКТУРА ТА ПЕДАГОГІЧНІ УМОВИ ФОРМУВАННЯ САМООСВІТНЬОЇ КОМПЕТЕНТНОСТІ МАЙБУТНІХ ФАХІВЦІВ}

У статті розглянуто проблеми формування самоосвітньої компетентності майбутніх фахівців. Висвітлено різні підходи до визначення поняття "самоосвіта" та виділено етапи самоосвіти. 3'ясовано сутність поняття “самоосвітня компетентність". Виділено компоненти самоосвітньої компетентності: мотиваційний, організаційний, проиесуальний, контрольно-рефлексивний. Виділено етапи формування самоосвітньої компетенції. Проаналізовано різні підходи до виділення педагогічних умов, щяо сприяють ефективному формуванню самоосвітньої компетентності.

Ключові слова: самоосвіта, самоосвітня компетентність, етапи, компоненти, педагогічні умови. Jim. 12.

Nataliya Samaruk, Ph.D.(Pedagogy), Associate Professor of the Higher Mathematics and Computer Applications Department Khmelnytskiy National University

\section{STRUCTURE AND PEDAGOGICAL CONDITIONS OF FORMING THE SELF- EDUCATIONAL COMPETENCE OF FUTURE SPECIALISTS}

The problems of formation of self-educational competence of future specialists in the article are considered. Different approaches to the definition of the concept "self-education" as a process of self-mastery of knowledge is highlighted. The stages of self-education, which passes personality throughout life, are highlighted. The essence of the concept "self-education competence of future specialists" is clarified. Different approaches to the definition of the concept "self-educational competence" are considered, which is interpreted as an integrative quality of personality, as ability and readiness for self-development. The structural units of self-educational competence are revealed: self-motivation - self-organization - self-control - self-improvement-self-development. The component composition of self-educational competence is highlighted. The components are: motivational (desire, installation for self-improvement), organizational (clear construction of self-educational activity), procedural (functionality of knowledge, skills, skills, independent improvement), control and reflexive (self-analysis and self-assessment, selfcontrol and self-regulation, reflection). The process offormation of self-educational competence of future specialists is researched. The stages of formation of self-educational competence are as follows: the first (actualization of motives, search for necessity and meaning in self-education), the second (improvement of the experience of selfeducation), the third stage (understanding of the significance of self-education, which becomes an inalienable 